\title{
Editorial for an official journal of the American association of pharmaceutical scientists
}

\author{
Christopher M. Riley
}

I am delighted and honored to have been selected as the first Editor-in-Chief of AAPS Open, an open-access journal devoted to the rapid publication of quality articles in the pharmaceutical sciences. The journal will be a global forum for the barrier-free publication of reports of original research, as well as other significant work that demonstrates applications of scientific concepts and techniques across the entire breadth of the field. Thus AAPS Open will provide an important outlet for members of AAPS sections and focus groups to publish papers of interest to their communities, as well as for scientists throughout the field.

All AAPS Open articles will be fully peer reviewed by scientists with extensive knowledge in the subject matter. The editorial team, consisting of the associate editors and myself, has been aligned with the sections of AAPS to ensure that all aspects of the pharmaceutical sciences are covered, including but not limited to pharmaceutical and biomedical analysis, quality control, quality assurance, pharmaceutical biotechnology, biopharmaceutics, clinical pharmacology, translational research, drug discovery and its interface with drug development, formulation design, manufacturing science and engineering, physical pharmacy, pharmacokinetics, pharmacodynamics, drug metabolism, and regulatory affairs.

I want to thank the following eight well-known pharmaceutical scientists for agreeing to join the AAPS Open editorial team as associate editors: Nagesh Bandi (Pfizer), Varsha Bhatt-Mehta (University of Michigan), Panos Constantinides (BioPharmaceutical \& Drug Delivery Consulting), Nikoletta Fotaki (University of Bath), Jayne Hastedt (JPD Pharma), Tim Hickling (Pfizer), Jaime Marach (CUSTOpharm) and Jean Lee (BioQualQuan). We are in the process of assembling a noteworthy editorial board comprised of internationally recognized pharmaceutical scientists who will help guide the journal.

Correspondence: criley@rileyandrabel.com

Riley and Rabel Consulting Services, Maryville, MO, USA
One of the obvious advantages of publishing in a completely open-access journal is the speed of publication. Given the ever-increasing pace of drug development, we hope that this advantage will encourage the publication of critical issues in drug development and stimulate lively discussions. AAPS Open will provide an opportunity for pharmaceutical scientists to share their experiences during the normal course of drug development as well as original research articles, reviews, opinions, commentaries, and industry best practices. We also encourage the submission of protocols of general interest and databases. The journal is open for submissions now. Membership in AAPS is not a requirement for publication in AAPS Open, and we look forward to receiving articles for consideration that will be of interest to everyone involved in the drug research and development.

Received: 8 October 2015 Accepted: 8 October 2015

Published online: 19 November 2015

Submit your manuscript to a SpringerOpen ${ }^{\odot}$ journal and benefit from:

- Convenient online submission

- Rigorous peer review

- Immediate publication on acceptance

- Open access: articles freely available online

- High visibility within the field

Retaining the copyright to your article

Submit your next manuscript at $\boldsymbol{\wedge}$ springeropen.com 